\title{
AN ANALYSIS INTO THE STRUCTURE, VALIDITY AND RELIABILITY OF THE CHILDREN'S ATTITUDES TOWARDS INTEGRATED PHYSICAL EDUCATION- REVISED (CAIPE-R)
}

\author{
Maria João Campos ${ }^{1}$, José P. Ferreira ${ }^{1}$ Martin E. Block ${ }^{2}$ \\ 1. University of Coimbra, Portugal \\ 2. University of Virginia, USA
}

The main purpose of the present research is to test the validity and reliability of the revised version of the Children's Attitudes towards Integrated Physical Education-revised - CAIPE-R (Block, 1995), using a Portuguese sample. Participants were 683 middle school students without disabilities $(\mathrm{n}=316$ females and $n=367$ males, between 11 and 16 years, mean age $13.31 \pm 1.10)$. The CAIPE-R measures students 'attitudes toward including students with a disability in general physical education (GPE). The estimation of reliability was ascertained using the coefficient alpha for the two subscales and was reported at 0.72 and 0.48 respectively. Exploratory factor analysis revealed a slightly different factorial organization with a small number of cross loadings. The internal consistency and the validity of the CAIPE-R have been adequately tested, replying the original structure presented by Block (1995). Results points out that the Portuguese version of the CAIPE-R is a valid and reliable instrument to assess attitudes of students without disabilities toward including peers with disabilities in their GPE classes, providing significant interest and adequacy for the use of CAIPE-R in future researches.

Keywords: validity, reliability, CAIPE-R, attitudes, inclusion

\section{INTRODUCTION}

Perhaps the most transformative school reform in the past thirty years has been the movement away from educating students with disabilities in special schools and special classes to inclusive settings where students with disabilities are educated alongside peers without disabilities in regular classrooms where adequate resources for enabling the success for all students is warranted (Block, 2007; Kennedy \& Horn, 2004; Lipsky \& Garnter, 1997). The rationale for inclusion is based on benefits to children with disabilities, children without disabilities, and to the school and greater community as a whole (Block, 2007; Karagiannis, Stainback \& Stainback, 1996; Stainback \& Stainback, 1991). "The fundamental principle of inclusive schools is to all children should learn together, wherever possible, regardless of the difficulties and differences that show. Schools should accommodate all children regardless of their physical, intellectual, social, emotional, and linguistic or other "(UNESCO, 1994).

While this movement towards inclusion was mainly focused in the United States, this trend towards inclusive education has begun to take hold worldwide and according with recent reviews (e.g. Klavina \& Kudlacek, 2011; O'Brien, Kudlacek \& Howe, 2009) Europe is in the process of making a positive move towards greater inclusion of students with both mild to severe disabilities. In same European Countries such as Portugal, public policies require all students with disabilities to be included in regular school settings. Since the mid-twentieth century to the present days, development was supported by numerous legislative measures (e.g. Public Laws PL 317/76; Education Law, 1986; PL 35/90; PL 105/97; PL 319/91; PL 3/2008) revelling a clear political effort towards inclusion and providing an effective support for the educational needs of many students with disabilities.

$\mathrm{PE}$ and sports play an important role in European society and is considered as a growing social phenomenon which makes an important contribution to the EU's strategic objectives of solidarity, although the current situation in Europe requires substantial improvements towards the philosophy and the practice of inclusion of students with disabilities into PE classes (Klavina \& Kudlacek, 2011). 


\section{Inclusion in General Physical Education}

General physical education (GPE), as a fundamental subject in the school curriculum, should not remain outside the inclusive movement (Rodrigues, 2003) and it may be used as a fundamental tool to transform regular school into a more inclusive environment. According to Frese and Yun (2007), GPE is an effective academic area to promote abilities over disabilities and help students to understand one another and their capabilities. Block (2007) extended this point by suggesting GPE offers opportunities for social acceptance and interaction between students with and without disabilities that are not available in other places in the school due to the unique instructional setting that often pairs students together in small groups or teams to work together for a common goal. It is recognized that both attitudes and intentions of classmates without disabilities, as documented by numerous studies in GPE play critical role in the successful inclusion of students with disabilities (Block \& Obrusnikova, 2007). In a recent review of literature (O'Brien, Kudlacek \& Howe, 2009) it is outlined that successful inclusion in physical education can take place effectively and moreover researches revealed that inclusion can be implemented without any negative impact on students with and without disabilities. To ascertain the impact of inclusion in PE classes is crucial to have reliable instruments to measure student's attitudes towards peers with disabilities in GPE.

There are some studies that have been published about the attitudes of students without disabilities towards inclusion in GPE. Among those the Children`s Attitudes Towards Integrated Physical Education - CAIPE-R (Block, 1995) is the most used instrument to measure the student's attitudes towards the inclusion of peers with disabilities in GPE. By focusing solely on attitudes toward inclusion in GPE, the CAIPE-R is ideally suited for regular and adapted physical educators who are concerned with the impact inclusion in GPE has on students without disabilities. In addition, the CAIPE-R could be used by researchers interested in studying and understanding the influence of different factors such as gender, age, type and severity of disability, types of contact (e.g., family, friend and classmate), specific training of peers without disabilities (Block, 1995). The original CAIPE inventory was validated on a sample of 44 participants from 6th grade, and the revised CAIPE-R inventory was validated on a sample of 208 participants from 5th and 6th grade. The CAIPE- $R$ is assumed to be a valid and reliable instrument for measuring attitudes of students without disabilities towards including students with disabilities within the physical education environment (Block, 1995). In spite of its use in different cultures (e.g. USA, Israel, Czech Republic, Belgium and Greece) the psychometric properties of the instrument were not yet fully tested providing evidence for its generalized use as a valid psychometric instrument for the assessment of attitudes among children and youth. For example, Hutzler and Lezi (2008) validated the Israeli version of CAIPE-R and findings showed that the internal consistency of the CAIPE-IL scale with 11 items (seven in the general subscale and four in the sport specific subscale) reached acceptable values, $(\alpha=.77$ and $\alpha=.62$ respectively). EFA was used and a bi-factor solution was computed accounting for $42 \%$ of the variance and $48 \%$ of the variance however CFA was not performed. Also, in the Czech version (Kudlacek, Ješina \& Wittmanova, 2011) CFA was not computed. Therefore, the main purpose of the present study is to test validity and reliability of the Portuguese version of the Children's Attitudes Towards Integrated Physical Education - Revised (CAIPE-R) (Block, 1995) as well as to focus on the psychometric properties of the instrument which were not fully tested using confirmatory factor analysis to assess the goodness-of-fit for the original two factors model.

\section{METHOD}

\section{Participants}

The global number of participants were 683 students ( $n=316$ girls and $n=367$ boys) selected from a convenience sample ranging from 11 to 16 years of age (mean age $13.31 \pm 1.10$ ) recruited from different state middle schools (7th to 9th grade) from rural and suburban areas in Portugal. All schools were recently inclusive schools, where students with different types of disability such as physical or mild intellectual disability attended preselected regular classes in an inclusive 
environment. Two different samples were used: to run the exploratory factor analysis (EFA) participants were 174 students, 81 girls and 93 boys (mean age 13.36 \pm 1.09 ). Confirmatory factor analysis (CFA) was run with 509 students, 235 girls and 274 boys (mean age 13.32 \pm 1.11 ).

The use of volunteers from a convenience sample is a clear limitation for the study assuming that those who accept to express their personal feelings and opinion about their inclusion attitudes may feel more comfortable and confident in their relationship with peers with disability. An effort was made to recruit participants from different backgrounds and geographic areas in order to assure the representativeness of the target population.

\section{Instrumentation}

A Portuguese version of the Children's Attitudes towards Integrated Physical Education - Revised CAIPE-R (Block, 1995) was used in this study. The CAIPE-R consists of (a) a description of a hypothetical student with a disability presented by a written vignette, (b) numerous questions related to students' demographics and experiences with individuals with disabilities (initial survey), (c) six or seven statements about including a student with a disability in GPE (general attitude subscale), and (d) five to seven optional statements about modifying rules of sports in GPE (sport-specific attitude subscale). Students respond to each statement using a 4-point Likert scale $(4=$ yes, $3=$ probably yes, $2=$ probably no, and $1=$ no). For coding purposes, the general statement 2 was coded in reverse. According to Block (1995), a single CAIPE-R attitude score was computed by summing scale statements or two separate scores (general physical education and sport modification) can also be calculated and analysed. The general attitude statements focus on beliefs toward the inclusion of students with disabilities in GPE. Similarly, the sport specific statements focus on beliefs toward modifications to group games. For scoring purposes, item 7 was deleted as previously suggested by Block (1995) with a total number of six general attitude statements and five sport specific statements used.

In international research, translation is extremely important especially if the questions are supposed to have the identical meaning to all participants (Saunder et al., 2007). Therefore the Portuguese version of the CAIPE-R was adapted and translated by two English speaking APA professionals following the procedures suggested by Vallerand (1989) using back translation together with suggestions made by Banville and Desoriers (2000) for the trans-cultural validation of psychological instruments including back translation by a professional English teacher.

In the adaptation process and in spite of the original instrument uses a description of a child with disability participating in a softball game, the present version was adapted describing a child with physical disability participating in a basketball game as basketball is a much more popular sport than baseball in the educational environments where the instrument was used to collect data, using Horvat, Block and Kelly (2007) adaptations for basketball.

\section{PROCEDURE}

Participants were tested in groups ranging from 20 to 30 individuals at the beginning or at the end of GPE classes with previous institutional approval and consent from the school deans. The questionnaire was administrated to volunteers by trained research teachers after a short briefing about the purpose of the study. Standardized instructions were given to all participants about confidentiality as well as about encouragement to ask for help. Individual attention was provided to participants aiming to clarify doubts and to reduce the final number of spoiled returns.

\section{Data Analysis}

The full range of descriptive statistics (frequencies, means and standard deviations) were calculated for both domains. An alpha level of .05 was used for all statistical tests. Validation of the CAIPE-R was undertaken using exploratory factor analyses (EFA) with a total sample of 174 participants (sample A). Principal components analysis with robust rotation was calculated in order to establish the independence and integrity of the CAIPE-R subscales in students population without disability. Factors with an eigenvalue of greater than one were selected. Factor loadings below 0.4 were eliminated for the sake of 
clarity and factor solutions explaining less than $40 \%$ of item covariance and fewer than three items in each factor were not given further consideration (Tinsley \& Tinsley, 1987).

Subscales internal consistency was assessed using Cronbach's alpha coefficients (Cronbach, 1951). Bivariate correlations were used to analyse the relationship between the CAIPE-R different subscales (general attitude subscale and the sport-specific attitude subscale) and the global attitude towards inclusion. Stepwise multiple regression was also used to assess the level of explained variance between the two subscales and the global attitude towards inclusion. Finally, a confirmatory factor analysis (CFA) using robust condition was calculated to test the goodness-of-fit for the original model. The goodness-of-fit is the most common way to establish both measurement and structural model validity. There are several fit measures assessing different aspects of model fit, categorized as absolute fit indices and incremental fit indices. Hair, Anderson,
Tatham and Black (2010) recommend the following goodness of fit indices to be reported for both measurement model and structural model fit: Chi square, degrees of freedom, one absolute fit index (e.g. goodness of fit index (GFI)), one incremental fit index (e.g. normed fit index (NFI)), and one badness of fit index (e.g. root mean square error of approximation (RMSEA)). Different indices are suited for different sample sizes and different numbers of observed variables. For example the standardized root mean residual (SRMR) is not suited for sample sizes above 250 and less than 12 observed variables (Hair et al. 2010).

\section{RESULTS}

Table 1 provides a comparison of subscale mean values and standard deviations from female and male middle school students in the present study (samples A and B) as well as from the original study (Block, 1995) with a similar sample.

\section{TABLE 1}

Means and standard deviations from CAIPE-R subscales analysed by gender

\begin{tabular}{lccccccccc}
\hline & & \multicolumn{2}{c}{$\begin{array}{c}\text { Sample A } \\
\mathrm{n}=174\end{array}$} & \multicolumn{2}{c}{$\begin{array}{c}\text { Sample B } \\
\mathrm{n}=509\end{array}$} & \multicolumn{2}{c}{ Total sample } \\
$\mathrm{n}=683$ & \multicolumn{3}{c}{$\begin{array}{c}\text { Block, 1995 } \\
\mathrm{n}=208\end{array}$} \\
\hline Dimension & Gender & $\mathrm{M}$ & $\mathrm{SD}$ & $\mathrm{M}$ & $\mathrm{SD}$ & $\mathrm{M}$ & $\mathrm{SD}$ & $\mathrm{M}$ & $\mathrm{SD}$ \\
\hline Global & Female & 3.28 & .29 & 3.37 & .28 & 3.34 & .28 & 2.89 & .38 \\
Attitude & Male & 3.12 & .42 & 3.27 & .40 & 3.25 & .39 & 3.13 & .28 \\
General & Female & 3.07 & .43 & 3.23 & .38 & 3.17 & .39 & 3.09 & .60 \\
PE & Male & 2.88 & .56 & 3.12 & .52 & 3.08 & .51 & 2.80 & .67 \\
Sport & Female & 3.52 & .32 & 3.54 & .33 & 3.53 & .32 & 3.17 & .66 \\
Specific & Male & 3.41 & .46 & 3.47 & .43 & 3.47 & .42 & 3.12 & .68 \\
\hline
\end{tabular}

Descriptive results analysed by gender reveal that female participants (samples A, B and total) present higher mean values for general PE and sport specific subscales as well as for the global attitude than their male colleagues, revealing that females have more positive attitudes towards inclusion of children with disabilities in regular PE classes than males. Further comparison between samples revealed that both male and female participants presented higher mean values for general PE and sport specific subscales as well as for the global attitude than those reported by Block
(1995) for the male and female USA sample, revelling more positive attitudes to inclusion of children with disability in regular PE classes than their American mates.

\section{Dimensionality}

Initial validation of the CAIPE-R was undertaken using exploratory factor analyses, Principal Components Analysis extraction method with Varimax rotation, to analyse the replication of the original structure of the instrument suggested by Block (1995) with a total sample of 174 participants $(n=81$ girls and 
$\mathrm{n}=93$ boys, mean age $13.36 \pm 1.09$ ). The results of the preliminary exploratory factor analysis from the middle school students are presented in table 2.

\section{TABLE 2}

Principal components factor loadings for CAIPE-R items $(n=174)$

\begin{tabular}{|c|c|c|c|c|}
\hline Subscale & $\begin{array}{l}\text { Item } \\
\text { number }\end{array}$ & F1 loadings & F2 loadings & F3 loadings \\
\hline General PE & $\begin{array}{l}1 \\
2 \\
3 \\
4 \\
\end{array}$ & $\begin{array}{l}.702 \\
.538 \\
.698 \\
.562 \\
\end{array}$ & & \\
\hline Sport Specific & $\begin{array}{l}5 \\
6 \\
7 \\
8 \\
11 \\
\end{array}$ & {$[.364]$} & $\begin{array}{l}{[.572]} \\
{[.608]} \\
.367 \\
.344 \\
.689 \\
\end{array}$ & \\
\hline F3 & $\begin{array}{l}9 \\
10 \\
\end{array}$ & & & $\begin{array}{l}.876] \\
{[.569]} \\
\end{array}$ \\
\hline Eigenvalue & & 3.004 & 1.825 & 1.325 \\
\hline$\%$ Variance & & 16.849 & 13.895 & 10.643 \\
\hline Cum. \% Variance & & 16.849 & 30.743 & 41.386 \\
\hline
\end{tabular}

The three factor solution explained a total of $41.4 \%$ of the variance among the sub scale items. The majority of items loaded on their intended factors, general PE and sport specific sub-domains were clearly defined with four out of six and three out of five items loading on their intended factor. Items 5 and 6, originally allocated to general PE sub-domain cross loaded in sport specific sub-domain with loading values of .57 and .61 respectively, while items 9 and 10 originally allocated to sport specific sub-domains cross loaded in factor three with loading values of .88 and .67 respectively.

\section{Reliability}

Hair et al. (2010) defined reliability as an assessment of the degree of consistency between multiple measures of a variable. Internal consistency and reliability was undertaken for each sub-scale using Cronbach Alpha values (Cronbach, 1951) for attitude scales as recommended by Thomas and Nelson (2001). General PE sub-scale showed a good internal consistency with a coefficient Cronbach Alpha value of .72 while sport specific sub-scale showed a poor internal consistency with Cronbach Alpha value of .48, according to Hair et al. (2010).

\section{Confirmatory factor analysis}

Confirmatory factor analysis (CFA) was conducted to assess the goodness-of-fit of the original CAIPE-R factorial model with a second sample of 509 Portuguese middle school students $(n=235$ girls and $n=274$ boys, mean age $13.30 \pm 1.11$ ). Figure 1 represent the factorial structure for CAIPE-R with the general physical education and the sport specific subscales as two unobserved latent variables each one associated to a group of observed variables and designated as factors, as well as the covariance values between each pair of variables and the residual errors in the prediction of an observed factor.

Coefficients associated with single-headed straight arrows are standardized regression weights that indicate the effect of one variable on another and the double-headed curved arrow represents the correlation between variables. The covariance values in the factorial structure of CAIPE-R with two unobserved variables, ranged from .36 to .61 for "general physical education" and from .18 to .61 for sport specific subscales.

CFA was run with an eleven items model and produced improved values for the $\chi^{2}$, CFI, GFI, AGFI, SRMR and RMSEA indices. The $\chi^{2}$ value obtained (148.419) differs 
significantly from the independence model $(\mathrm{p}<$ .001). CFI, GFI and AGFI index values were $.81, .95$ and .92 respectively. $\chi^{2} / \mathrm{df}$ value, a ratio value used to assess the level of adjustment to the model was higher than 3.0 $\left(\chi^{2} / \mathrm{df}=3.45\right)$. Additionally, SRMR index showed a cut-off value lower than 0.08 (SRMR=0.03) and RMSEA also showed a cutoff value close to 0.06 (RMSEA=0.067) as recommended by $\mathrm{Hu}$ and Bentler (1999).

\section{FIGURE 1}

Confirmatory factor analysis of the two factors structure for the CAIPE-R scale

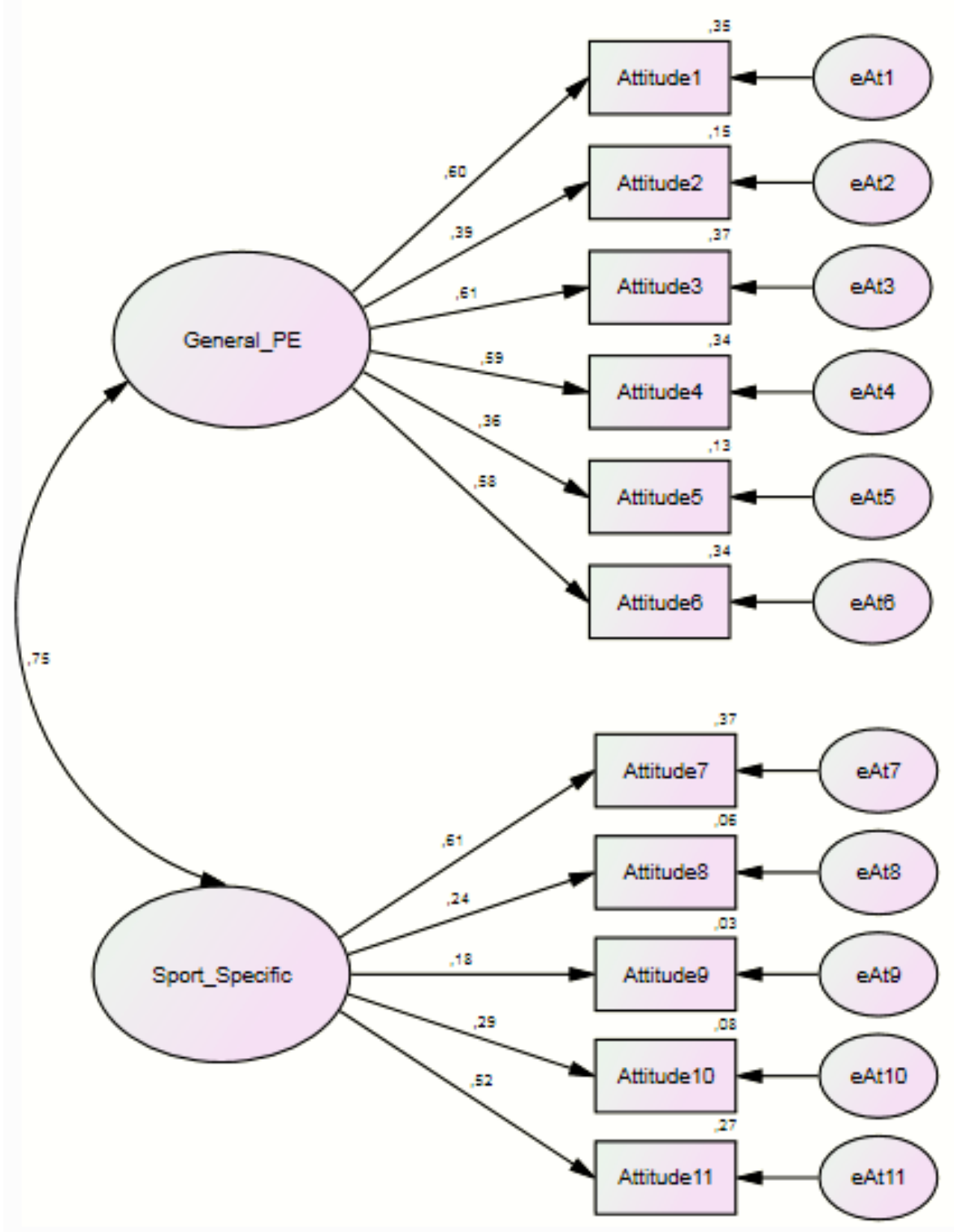




\section{DISCUSSION}

The main purpose of this study was to investigate validity and reliability of the Children's Attitudes Towards Integrated Physical Education-revised - CAIPE-R using a sample of middle school students. Preliminary factorial structure, tested using sample A participants $(n=174)$ revealed a final factor solution explaining $41.4 \%$ of the variance among the subscale items. Results from Block's study revealed Cronbach Alpha values of .78 for the general attitude subscale and .67 for the sport specific subscale. In the Israeli version of the CAIPE-R and after omitting two items, Hutzler and Levi (2008) reported Cronbach's alpha coefficients of .77 in the general subscale and .62 in the sport specific subscale. The Czech version (Kudlacek, Ješina \& Wittmanova, 2011) showed a high internal consistency $(\alpha=0.84)$ in the total scale. In the present study internal consistency seemed to be different among subscales, general PE subscale showed a good internal consistency with a Cronbach Alpha coefficient of .72 similar to those reported for the USA and Israeli populations while sport specific subscale showed a much poor internal consistency with a Cronbach Alpha coefficient value of.48, lower than those reported for this subscale in the studies previously mentioned.

Principal components factor analysis results provide a moderate support for the two sub domain factor model of CAIPE-R proposed by Block (1995) that has been confirmed in other studies with children without disabilities (Hutzler \& Levi, 2008; Panagiotou et al., 2008; Obrusníková, Válková \& Block, 2003) in different cultural and educational settings, however the confounding of items from general PE into sport specific subscales and in particular the strong cross loading of item 9 into a third factor (F3) requires further investigation as the content meaning of this particular item - John could stay in the keyhole longer (five seconds instead of three) - may not be interpreted similarly in different cultures. It appears that Portuguese students are not comfortable in changing rules that much. Probably this item should be changed to another sport specific item. It is interesting to see that in CFA this is the item with lower covariance value (.18). In contrast, the Czech version (Kudlacek, Ješina \& Wittmanova,
2011) items were structured in a slightly different way, and item 10 did not load and the authors suggested deleting this item. Also in Czech version, the fifth and sixth items were loaded to the second component and those 6 items were entitled "Beliefs about actual behaviour". In our understanding further research is needed in order to understand those different cross loadings. As said before, no previous study ran CFA for CAIPE-R. CFA was run in order to show different fit indices values considered as relevant for the CAIPE-R model evaluation. CFI and AGFI index values were .81 and .92 respectively, showing an acceptable cut-off criteria $(\mathrm{Hu} \&$ Bentler, 1999). The $\chi^{2} / \mathrm{df}$ value showed a poor adjustment (Joreskog, 1969) for this specific criterion. SRMR index showed a cut-off value lower than 0.08 (SRMR=0.03) and RMSEA also showed a cut-off value close to 0.06 (RMSEA $=0.067$ ) as recommended by $\mathrm{Hu}$ and Bentler (1999) providing important evidence of two cut-off index values that clearly contribute to a lower type II error rate and provide good support for the model fit, showing this survey is a valid and reliable instrument with the Portuguese middle school student's sample.

In many European countries (e.g. Germany, France, Italy, the Netherlands, Spain or Portugal, among many others) there is still very few information about students personal feelings on inclusion available for comparison. Further research is needed on attitudes, feelings and intentional behaviour of students without disability towards inclusion of peers with disability in GPE classes. Moreover, this type of information will provide important support to schools, teachers, staff members, school managers and legislators to define inclusive and motivational strategies powerful enough to modify stigma, segregational attitudes and inappropriate behaviours aiming to promote a more positive and inclusive educational environment.

As previously mentioned, legislation norms are not strong enough (just by themselves) to produce change towards an inclusive education setting and the assessment of attitudes and behaviours may be seen as the starting point for a profound curricula change in GPE, including the enclosure of new events and topics such as an introduction to Paralympic sports, the Paralympic school day as well as 
other adapted physical activities and specific adapted sport and exercise information both in regular curricula and PE school manuals, as it has already been done in some others countries (e.g. United States of America, Greece; Israel; Czech Republic and Belgium). This type of programs may be seen as models and should be significantly expanded and strengthened through evidence-based studies. Future research should focus attention into a deeper and more detailed analysis of these particular intervention programs as well as on the duration of these attitude changes over time. The use of valid instruments such as the Portuguese version of the CAIPE-R seems to be very relevant in order to ascertain the impact of awareness programs in Portuguese schools.

\section{Perspective}

In summary, results from the present study showed that indices of overall model fit moderately support the two factors structure for the attitudes scale with four out of six criteria reaching the cut-off intervals acceptable to confirm the model fit, providing important evidence for the validity and reliability of the instrument. Therefore, present results confirm CAIPE-R as a valid and reliable instrument to assess attitudes of students without disabilities toward including peers with disabilities in their GPE classes, promoting additional interest and adequacy for the use of CAIPE-R in future research actions with this scope.

\section{Acknowledgements}

The authors would like to thank César Rodrigues, Fabiana Gonçalves, Gonçalo Gomes, Joana Amaral, José Godinho and Marco Nobre for their contributions in data collection.

\section{REFERENCES}

Banville, D., \& Desoriers, P. (2000). Translating Questionnaires and Inventories Using a Cross-Cultural Translation Technique. Journal of Teaching in Physical Education, 19, 374-378.

Block, M.E. (1995) Development and validation of the children's attitudes towards integrated physical education- revised. Adapted Physical Activity Quarterly, 12, 60-70.

Block, M., \& Obrusnikova, I. (2007). "Inclusion in Physical Education":

A review of the literature from 1995-2005. Adapted Physical Activity Quarterly, 24 (2), 103-124.

Block, M. E. (2007) A teacher's guide to including students with disabilities in regular physical education (2nd ed.). Baltimore, MD: Paul H. Brookes Publishing.

Conatser, P., Block, M.E., \& Lepore, M. (2000). Aquatic instructors'attitudes toward teaching students with disabilites. Adapted Physical Activity Quarterly, 17, 173-183.

Frese, E. (2006). Effects of Disability Awareness Activities on Acceptance and Knowledge of Secondary Level Students. Master Thesis, Oregon State University, USA.

Frese, E., \& Yun, J. (2007). Effects of Disability Awareness on General Acceptance, Acceptance of Inclusive Physical Education, and Knowledge of Secondary Level Students in Physical Education. AAHPERD National Convention and Exposition.

Hair, J.F., Anderson, R.E., Tatham, R.L., \& Black, W.C. (2010). Multivariate data: Analysis with readings. New Jersey: Prentice-Hall.

Hamilton, E.J., \& Anderson, S. (1983). Effects of leisure activities on attitudes toward people with disabilities. Therapeutic Recreation Joumal, 17(3), 50-57.

Hazzard, A. (1983). Children's Experience with Knowledge of, and Attitude toward Disabled Persons, Journal of Special Education, 17(2), 131-139.

Hu, L., \& Bentler, P.M. (1999). Cut-off criteria for fit indexes in covariance structure analysis: Conventional criteria versus new alternatives. Structural Equation Modeling, 6(1), 1-55.

Hutzler, Y., \& Levi, I. (2008). "Including Children with Disability in Physical Education: General and Specific Attitudes of High-School Students". European Journal of Adapted Physical Activity, 1 (2), 21-30.

Hutzler, Y. (2003). Attitudes toward the participation of individuals with disabilities 
in physical activity: A review. Quest, 55, 347-373.

Joreskog, K.J. (1969). A general approach to confirmatory maximum likelihood factor analysis. Psychometrica. 34, 183-202.

Karagiannis, A., Stainback, W., \& Stainback, S. (1996). Rationale for inclusive schooling. In Stainback S and Stainback W (eds.), Inclusion: A guide for educators Baltimore: Paul H. Brookes, 3-16.

Klavina, A., \& Kudlacek, M. (2011). Physical Education for Students with Special Education Needs in Europe: Findings of the EUSAPA Project. European Journal of Adapted Physical Activity, 4 (2), 46-62.

Kennedy, C., \& Horn, E.M. (2004). Including students with severe disabilities. Boston: Allyn and Bacon.

Kudlacek, M., Ješina, O., \& Wittmanova, J. (2011). Structure of a questionnaire on childrens attitudes towards inclusive physical education (CAIPE-CZ). Acta Universitatis Palackianae Olomucensis Gymnica 41(4), 43-48.

Lipsky, D., \& Gartner, A. (1997). Inclusion and school reform: Transforming America's classrooms. Baltimore: Paul H. Brookes.

Megginson, N., \& Lavay, B. (2001) Providing disability sport opportunities in adapted physical education. Palaestra: 17 (2), 20-26.

O'Brien, D., Kudláček, M., \& Howe, P. (2009). A Contemporary Review Of English Language Literature On Inclusion Of Students With Disabilities In Physical Education: A European Perspective. European Journal of Adapted Physical Activity, 2(1), 46-61.

Obrusníková, I., Válková, H., \& Block, M.E. (2003). Impact of Inclusion in General Physical Education on Students Without disabilities. Adapted Physical Activity Quarterly, 20, 230-245.

Panagiotou, A., Evaggelinou, C., Doulkeridou, A., Mouratidou, K., \& Koidou, E. (2008). Attitudes of 5th and 6th grade Greek Students Towards the Inclusion of Children with Disabilities in Physical Education Classes After a Paralympic Education Program. European Journal of Adapted Physical Activity, 1 (2), 31-43.
Rodrigues, D. (2003). A Educação Física perante a Educação Inclusiva: reflexões conceptuais e metodológicas. Boletim da Sociedade Portuguesa de Educação Física, 24/25, 73-81.

Sable, J. (1995). Efficacy of physical integration, disability awareness, and adventure programming on adolescents' acceptance of individuals with disability. Therapeutic Recreation Journal. 29, 206217.

UNESCO (1994). Salamanca Statement and Framework for Action. World Conference on Special Needs Education: Access and Quality.

Stainback, W., \& Stainback, S. (1991)

$A$ rationale for integration and restructuring: A synopsis. In Lloyd JW, Singh NN and Repp AC (eds.) The regular education initiative: Alternative perspectives on concepts, issues and models. Sycamore: Sycamore, IL. 225-239.

Thomas, J., \& Nelson, J. (2001). Research methods in physical activity (4th edition), Champaign, IL: Human Kinetics.

Tinsley, R., \& Tinsley, D. (1987). Uses of factor analysis in counselling psychology research. Journal of Counselling Psychology, 4, 414-424.

Vallerand, R. J. (1989). Vers une méthodologie de validation transculturelle de questionnaires psychologiques: implications pour la recherche en langue française. Psychologie Canadienne, 30, 662-680.

\section{Corresponding author:}

Maria J. Campos

E-mail address: $\underline{\text { mjcampos@fcdef.uc.pt }}$ 